\title{
Lymph Trunk
}

National Cancer Institute

\section{Source}

National Cancer Institute. Lymph Trunk. NCI Thesaurus. Code C33485.

A lymphatic vessel that is formed by efferent lymphatic vessels and empties lymph into the lymphatic ducts. 